PUBLIC ABSTRACT

FIRST NAME: HOWARD

MIDDLE NAME: DAVID

LAST NAME: THOMAS

DEGREE: MASTERS OF SCIENCE

ACADEMIC PROGRAM: CIVIL ENGINEERING

ADVISER'S FIRST NAME: HANI

ADVISER'S LAST NAME: SALIM

CO-ADVISER'S FIRST NAME:

CO-ADVISER'S LAST NAME:

GRADUATION TERM: FALL

GRADUATION YEAR: 2006

\title{
TITLE: NON-DESTRUCTIVE EVALUATION OF WOOD UTILITY POLES USING COMPUTED AXIAL TOMOGRAPHY IMAGING
}

Of the more than 130 million wooden utility poles in service, there are approximately 2 million that are replaced annually. A quick, yet accurate non-destructive method of evaluation of the in-service poles could provide substantial savings by reducing both the number of replacements and the number of failures. Research has been conducted to determine the possible use of Computerized Axial Tomography or CAT Imaging for pole evaluation. This involved correlating actual physical strengths determined by destructive testing with predicted strengths that were calculated using basic laws of material behavior and the cross-sectional scan image of wood density values that were measured using the prototype CAT scanner. The statistical analysis of the correlation between the measured and predicted strengths used a data set of 31 pole specimens.

A predictive model was developed assuming several different relationships between wood density and the assumed stress vs. strain diagrams. The predictive model also made adjustments for areas of decay and the average moisture content of the wood specimens. The most accurate predictive model developed had average error of estimate of approximately $24 \%$ and a coefficient of variation for the difference between the measured and predicted values of approximately $21 \%$. 